\title{
Bernhard von Waging (+ 1472), ein Theologe der Melker Reformbewegung
}

\author{
Monastische Theologie im 15. Jahrhundert?
}

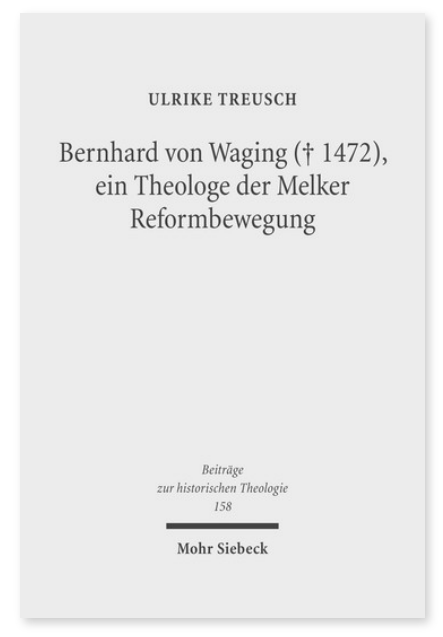

2011. XIX, 356 Seiten. BHTh 158

ISBN 978-3-16-151068-7

DOI 10.1628/978-3-16-151068-7

eBook PDF 119,00€

ISBN 978-3-16-150842-4

Leinen $119,00 €$
Ulrike Treusch fragt anhand von Person und Werk Bernhards von Waging († 1472) nach der monastischen Theologie im 15. Jahrhundert. Bernhard von Waging aus dem Kloster Tegernsee war einer der bekanntesten Vertreter der benediktinischen Reformbewegung von Melk. Er wirkte nicht nur als praktischer Reformer, sondern vor allem als Autor theologischer Reformschriften. Auch seine Korrespondenz mit Nikolaus von Kues und Nikolaus von Dinkelsbühl zeigt sein Anliegen einer Kloster- und Kirchenreform. Die Autorin untersucht Bernhards theologische Schriften in ihrem zeitgenössischen Kontext und in der Rezeption scholastischer wie monastischer Theologie. Sie legt mit dieser Arbeit die erste Monographie zu Bernhard von Waging vor und bietet aus der Untersuchung auch unedierter lateinischer Schriften eine neue Perspektive auf die Reformdiskussion des 15. Jahrhunderts und die spätmittelalterliche monastische Theologie.

Ulrike Treusch Geboren 1971; Studium der Evangelischen Theologie und Germanistik in Tübingen und Jerusalem; seit 2007 Dozentin für Theologie am CVJM-Kolleg und seit 2009 auch an der CVJM-Hochschule, Kassel; 2010 Promotion. https://orcid.org/0000-0003-4955-2212
Jetzt bestellen:

https://mohrsiebeck.com/buch/bernhard-von-waging-1472-ein-theologe-der-melker-reformbewegung-9783161510687? no_cache=1

order@mohrsiebeck.com

Telefon: +49 (0)7071-923-17

Telefax: $+49(0) 7071-51104$ 